Work related fatalities

\section{Reporting of work related fatalities: bystanders and commuters}

\section{J Langley}

\section{New approaches to recording work related deaths may provide important opportunities for reducing injury}

$\mathrm{T}$ his issue of the journal focuses on occupational injury and features selected papers from the National Occupational Injury Research Symposium (NOIRS) held in Pittsburgh in October 2003 (see p 195 for a commentary on the meeting). Readers might also like to consult the NOIRS website (http://www.cdc.gov/niosh/ noirs/noirsmain.html) where there is a list of abstracts from the recent conference and those in 2000 and 1997.

Among the 2003 abstracts is one by Alberg entitled "Reported workplace fatalities: how complete is the picture?" It states "The provincial Workplace Safety and Health Division (WSH), Department of Labour in the province of Manitoba, Canada, has the responsibility for tracking fatalities in all workplaces. The system collects information on both workers and general public who die at, or as the result of, a workplace and its hazards".

The (non-working) general public in this context are often referred to as "bystanders" and in the Manitoba case are defined as follows: "a person other than a worker who is killed as a result of exposure to a workplace hazard, but who was not working for or in that workplace at the time of death". ${ }^{1}$

An example of a bystander death would be if a member of the public walks past a building site and a piece of scaffolding falls onto them and kills them. In this case the death clearly arose directly as a result of a work process. Capturing deaths such as this in a work related fatal database is very sensible and to be encouraged.

In the hypothetical scaffolding example, presumably implicit in the decision to record the death is the notion that there was fault on the part of some other person or agency (that is, the construction company should have procedures in place to ensure this could not happen). But should we record those deaths where the converse was the case? Deaths have occurred where children have climbed into apparently adequately fenced quarries, or people have wandered onto rail goods yards-should these be considered bystander deaths? Motor vehicle crashes on public roads raise particular problems. For example, consider the situation where a member of the public is driving their car, is distracted, wanders over the centre line and has a head on crash with a logging truck. In this case, some would argue that this should not be considered work related as there was no fault arising from the work process. Alternatively one could argue that this situation should be considered work related on the grounds that work processes have increased the probability of death given there is collision between two vehicles on the road.

Consideration of time between the creation of the hazard and the fatal outcome would also appear to be a consideration. For example, a worker may have made an error in the assembly of a plane. Five years later that plane crashes due to the assembly error and a member of the public dies. Should this be counted as a work related bystander death? On the face of it, it is hard to argue against this, but it raises many practical difficulties when trying to conduct a study of work related death.

Consideration of the inclusion of commuters in work related fatality statistics is arguably more contentious. There is a strong case for including them when it can be shown that work directly contributed to their death. Consider for example the employer of a nurse who has asked that nurse to work a series of 12 hour shifts without a day off over a seven day period. At the end of the seventh shift while driving home the nurse falls asleep, her vehicle drifts across the road and crashes, and she dies. But what if a direct link cannot be shown between employer policies and practices and the death?

A colleague and myself were on a 7:00 am flight recently on our way to a meeting to present to government agencies the findings of the first attempt to estimate the burden and nature of work related traffic crashes in New Zealand. ${ }^{2}$ This work was stimulated by work in Australia $^{3}$ and the USA ${ }^{4}$ which sug- gested that work related traffic crashes could represent the biggest category of work related deaths. In that study we identified three classes of victim: workers, commuters, and bystanders. We were running through our presentation on the plane and I noted the passenger next to me was taking more than an unusual interest. Finally he leaned over to me, introduced himself as an insurance assessor and advised that part of his job also included providing risk management for several companies with large vehicle fleets. The conversation went something like this:

Assessor: Commuting deaths (deaths of persons who died as a result of motor vehicle crashes while travelling to or from work) should not be considered work related deaths since they would not be working at the time of their death. JL: When do you consider most people commence work?

Assessor: When they get to their place of work

JL: Where do you work?

Assessor: From my home in Tauranga, I should be there by 11:00 am.

JL: So you're not working at the moment?

Assessor: Well of course I am, and my client is paying for this time.

JL: So if this plane went down and we all died-how should your death be classified: work or non-work related death?

Assessor: Work related death.

JL: What category of work related death: working, commuting, or bystander?

Assessor: Working.

JL: But what distinguishes your activity from my driving to work each day.

Assessor: My travel is a departure from the norm.

JL: So given that your drive to the airport was a departure from the norm presumably you would also consider this work activity?

Assessor: I need to think about that.

The conversation continued canvassing a wide range of issues including when work starts and finishes and if one has an employment contract which does not stipulate the hours within which one must be at work.

Thinking about such matters is something the assessor volunteered he had never done before. He is not alone in this respect. Many individuals/agencies working in the area simply ignore the 
issue, or offer a legal response such as "it's not covered by the Act".

Readers may well ask how big a problem are these bystander and commuting deaths? Arguably one of the most comprehensive and largest population based studies of work related deaths has been undertaken in Australia. The study included work related traffic fatalities. It showed that in the early 1990s there were about 200 bystander deaths per year-about $40 \%$ occurring in connection with some sort of formal workplace, and the remainder being bystander deaths resulting from collisions with working vehicles in which the working vehicles were deemed to be at fault. Another 400 deaths per year occurred in similar motor vehicle incidents where the nonworker's vehicle was considered at fault. There were an additional 150 commuting deaths per year, some of which were clearly related to work exposures such as end of shift drinking, fatigue from long shifts, and travel at night for shift workers. ${ }^{5}{ }^{6}$

Worldwide many of these deaths receive little or no attention from occupational health and safety authorities, usually because they are deemed to be outside the authority's formal or informal scope (as defined by legislation or custom), to be covered by other authorities, and/or not to really be "work related". This is well illustrated by a critique of the situation in Britain. $^{7}$

From a public health perspective it is important that we look beyond legislative and political boundaries in considering the impact of work related deaths. As in so many studies, the keys are to clearly establish what aspect of work related fatalities are of interest in the study; use clear definitions and apply them consistently; and collect the information in such a way that the data can be used to examine different aspects of the problem. Subject to resolving definitional issues, all commuting and bystander deaths should be separately identified. This allows one to more fully appreciate the impact of work, and to begin to consider how such deaths might be prevented, while at the same time meeting other legislative and political requirements. By taking a more inclusive approach to recording work related deaths we provide an opportunity for governments to identify new opportunities to reduce injury.
Injury Prevention 2004;10:193-194.

doi: 10.1136/ip.2004.006114

Correspondence to: Professor John Langley, Injury Prevention Research Unit, Dunedin School of Medicine, PO Box 913, Dunedin, New Zealand; john.langley@ipru.otago.ac.nz

\section{REFERENCES}

1 Manitoba Labour and Immigration Workplace Safety and Health Division. Manitoba: workplace injury and illness, statistics report for 2001-2002. Winnipeg: Manitoba Labour and Immigration Workplace Safety and Health Division, 2003:1-49.

2 New Zealand Environmental and Occupational Health Research Centre and Injury Prevention Research Unit. Work-related fatal traffic injuries in New Zealand 1985-1998. Dunedin: University of Otago, 2003:1-56.

3 National Occupational Health and Safety Commission. Work-related traumatic fatalities in Australia, 1989 to 1992. Canberra: National Occupational Health and Safety Commission, 1998.

4 US Department of Labour. Fatal workplace injuries in 1996. A collection of data and analysis. Washington, DC: Bureau of Labor Statistics, 1998.

5 Driscoll TR, Mitchell R, Mandryke J, et al. Workrelated fatalities in Australia 1989 to 1992: an overview. Journal of Occupational Health and Safety-Australia and New Zealand 2001;17:45-66.

6 Driscoll TR. The epidemiology of work-related fatalities in Australia. Sydney: University of Sydney, 2003.

7 Tombs S. Death and work in Britain. Sociological Review 1999;47:345-67. 